\title{
AÇÃO CIVIL PÚBLICA, DEFENSORIA PÚBLICA E DEMOCRATIZAÇÃO DO ACESSO À JUSTIÇA: REFLEXÕES SOBRE A LEGITIMIDADE ATIVA NA TUTELA DOS DIREITOS DIFUSOS E COLETIVOS
}

\author{
PUBLIC CIVIL ACTION, PUBLIC DEFENDER AND DEMOCRATIZATION OF ACCESS \\ TO JUSTICE: REFLECTIONS ABOUT THEACTIVE LEGITIMACY IN THE \\ PROTECTION OF DIFFUSE RIGHTS AND COLLECTIVE RIGHTS
}

João Víctor Pinto Santana

\begin{abstract}
Graduado em Direito pela Universidade Tiradentes. Membro do Grupo de Pesquisa Políticas Públicas de Proteção aos Direitos Humanos - UNIT- CNPq. E-mail: j.victorsantana@hotmail.com
\end{abstract}

Ilzver de Matos Oliveira

Doutor em Direito PUCRio. Mestre em Direito - UFBA. Professor Pleno do Mestrado em Direito da Universidade Tiradentes. Vice-líder e pesquisador do Grupo de Pesquisa Políticas Públicas de Direitos Humanos - UNIT-CNPq. E-mail: ilzver@gmail.com

Recebido em: 15/06/2016

Aprovado em: 17/08/2016

Doi: $10.5585 /$ rdb.v15i6.418

RESUMO: A busca pelo Judiciário para a solução dos conflitos é crescente, razão pela qual as instituições essenciais à justiça conquistaram posição de evidência no ordenamento jurídico. Com o surgimento das demandas coletivas, o processo civil se remodelou para atender aos anseios da coletividade. A alteração do art. $5^{\circ}$ da Lei no 7.347/85, ao incluir a Defensoria Pública no rol de legitimados para a propositura da ação civil pública, materializou a constitucionalização do processo civil, afastando, ainda mais, sua antiga concepção individualista. Diante disso, necessário analisar a legitimidade ativa da Defensoria Pública na tutela dos direitos difusos e coletivos à luz do acesso à justiça, por meio da teoria da adequacy of representation, atribuindose sentido amplo na concepção de hipossuficiência, com base nas recentes jurisprudências. Para tanto, utilizou-se de pesquisa bibliográfica qualitativa, através de referenciais teóricos e de jurisprudências envolvendo ação civil pública proposta pela Defensoria Pública na defesa dos direitos coletivos e difusos.

Palavras-Chave: Defensoria Pública; Ação Civil Pública; Acesso à justice.

\begin{abstract}
The search for the Judiciary System to solve conflicts is crescent, reason why the essential institutions to justice conquered evidence position at the legal system. With the emergence of collective judicial demands, the civil process was remodeled to attend the collective aspirations. The amendment of art. $5^{\circ}$ of the Law $n^{\circ} .7 .347 / 85$, that included the Public Defender in the legitimate roster for the proposal of the civil action, materialized the civil procedure as a constitucional task, removing even more its classic individualistic conception. Therefore, it is necessary to analyze the active legitimacy of the Public Defender in protecting the diffuse and collective rights through the spectrum of access to justice, through the theory of
\end{abstract}


adequacy of representation, assigning broad sense at the conception of low sufficiency, based on recent jurisprudences. Therefore, we used qualitative bibliographic research, through theoretical references and jurisprudences involving public civil action proposed by the Public Defender in the defense of collective and diffuse rights.

Keywords: Public Defender; Public Civil Action; Access to justice.

SUMÁRIO: Introdução; 1. Acesso à justiça: A limitação institucional da Defensoria Pública e os desafios para a Democratização do Acesso; 2. A legitimidade da Defensoria Pública para propor ações Civis Públicas: efetivação da Democratização do Acesso à Justiça e a Concretização dos Direitos Fundamentais; 3. Posicionamento do Supremo Tribunal Federal acerca da legitimidade ativa da Defensoria Pública na defesa de Direitos Difusos e Coletivos: Análise da ADI 3.943; Conclusão; Referências.

\section{INTRODUÇÃO}

Em um Estado Democrático de Direito torna-se crucial analisar o acesso à justiça, haja vista a busca do jurisdicionado para a solução dos conflitos. No tocante à assistência jurídica gratuita, o ordenamento jurídico evidencia a necessidade de concretizar, também, aos hipossuficientes economicamente, os direitos do devido processo legal e de defesa técnica jurídica, motivo pelo qual a Defensoria Pública conquista destaque no cenário jurídico pátrio.

Entretanto, a atuação da Defensoria também se evidencia em âmbito coletivo. Nesta seara, o escopo é, nitidamente, proporcionar, além de uma atuação estatal ampla, a efetivação de justiça na sociedade independentemente de divisão financeira de classes sociais. Diante disso, torna-se mister analisar como está sendo, hodiernamente, verificada esta prestação jurisdicional, principalmente em relação à coletividade. A crescente demanda processual relacionada à impetração de ações civis públicas propostas pela Defensoria Pública almeja a efetivação da norma jurídica constitucional, e é justamente este fato que fomenta o presente artigo.

Nesse sentido, deve ser analisar de que forma ocorre, atualmente, a legitimidade ativa da Defensoria Pública (conferida por meio da Lei $n^{\circ}$. 11.448/2007que alterou o art. $5^{\circ}$ da Lei $n^{\circ}$. $7.347 / 85$, incluindo no rol de legitimados), para a propositura de ações civis públicas especialmente nos casos de defesa dos direitos coletivos e difusos - sendo primordial, para tanto, verificar a evolução desta atuação na realidade processual brasileira.

O presente estudo se insere na seguinte problemática: A Defensoria está legitimada, de forma ampla, para tutelar, em juízo, qualquer direito coletivo em favor de qualquer grupo, ou, em contrario sensu, a legitimidade ativa conferida a esta relevante instituição essencial à justiça estaria limitada à defesa restrita dos direitos coletivos das pessoas necessitadas?

Para tanto, torna-se primordial a análise dos artigos constitucionais e infraconstitucionais, das recentes decisões dos tribunais superiores, bem como da atual doutrina relacionada à temática.

Este trabalho consiste ser de suma relevância à comunidade acadêmica, pois visa analisar a inserção da Defensoria Pública na categoria dos legitimados para a sua propositura de ação civil pública, passando esta mesma instituição a atuar, consequentemente, na defesa, em juízo, de direitos difusos e coletivos, por meio do instituto processual da ação civil pública, que é de crucial importância para a concretização dos direitos fundamentais.

Em relação à metodologia, utilizou-se de pesquisa bibliográfica qualitativa, por meio de referenciais teóricos e de jurisprudências envolvendo ações civis públicas propostas pela Defensoria Pública na defesa dos direitos coletivos e difusos à luz do acesso à justiça. 


\section{ACESSO À JUSTIÇA: A LIMITAÇÃO INSTITUCIONAL DA DEFENSORIA PÚBLICA E OS DESAFIOS PARA A DEMOCRATIZAÇÃO DO ACESSO}

Como consequência da ruptura da concepção individualista do direito ${ }^{1}$, os direitos transindividuais fizeram emergir inovações aos instrumentos processuais. Nesse diapasão, é primordial que a ordem jurídica reconheça que o acesso individual dos lesados à justiça seja substituído por um processo coletivo, apto a conduzir uma solução mais eficiente da lide.

A indivisibilidade e a indeterminação dos titulares são características intrínsecas dos direitos difusos, razão pela qual este rol de direitos se difere dos direitos coletivos em sentido stricto sensu, haja vista que neste último rol os titulares são determináveis. (MARINONI; MITIDIERO; ARENHART, 2015, p.411).

A constitucionalização do processo civil visa a efetivação e a concretização dos direitos, pois o processo não pode opor barreiras formais à sua concretização, especialmente ao serem analisados direitos fundamentais, à luz do acesso à justiça, da garantia constitucional da inafastabilidade do controle jurisdicional (art. $5^{\circ}, \mathrm{XXXV}$ ) e da efetiva prestação jurisdicional (FENSTERSEIFER,2015, 53).

Com o notório crescimento da tutela dos direitos fundamentais, o acesso à justiça tem se tornado uma forma de efetivação da cidadania e da isonomia entre os indivíduos, podendo ser considerado como "[...] um acesso materialmente informado pelo princípio da igualdade de oportunidades" (CANOTILHO, 2003, p. 501), tendo em vista que existe a garantia de resposta do judiciário diante dessas demandas sociais (individual e/ou coletiva).

Não há dúvida, portanto, que o sistema jurisdicional passou a possuir nítida credibilidade, haja vista que conquistou maior importância, após a Constituição de 1988, com o advento não somente de um Estado Democrático de Direito, mas também de instituições que possam resguardar, através da judicialização, tais direitos de maneira democrática e justa.

A sedimentação de um Estado Democrático de Direito, constitucionalmente garantido, é um verdadeiro "ponto de partida e nunca um ponto de chegada. Como ponto de partida constitui uma tecnologia jurídico-política razoável para estruturar uma ordem de segurança e paz jurídicas" (CANOTILHO, 2003, p. 233).

Justamente sob esta perspectiva de consolidação da segurança jurídica que, após a proteção atribuída pela $\mathrm{CF} / 88$, a Defensoria Pública passou a ter posição de destaque frente à tutela dos direitos individuais e coletivos, principalmente porque lhe foi conferida a função de proporcionar o acesso à justiça, com condições dignas, ao prestar assistência jurídica integral e gratuita aos que comprovarem insuficiência de recursos, bem como a função de orientar e defender juridicamente, em todos os graus, aos necessitados, conforme o art. $5^{\circ}$, LXXIV da $\mathrm{CF} / 88 \mathrm{c} / \mathrm{c}$ art. 134, caput da CF/88 (redação alterada com a Emenda Constitucional no80/2014) ${ }^{2}$. Entretanto, como veremos adiante, não é somente sob o enfoque específico da tutela do hipossuficiente que se verifica a competência da Defensoria, haja vista a grande atuação desta

\footnotetext{
${ }^{1} \mathrm{O}$ surgimento dos direitos relacionados à coletividade, tratados pelo ordenamento pátrio como direitos de terceira dimensão, "exigiu que o processo civil fosse remodelado para atender adequadamente às necessidades da sociedade contemporânea" (MARINONI; MITIDIERO; ARENHART; 2015, v.3, p.403). O dilema se instaurou justamente porque "a concepção tradicional do processo civil não deixava espaço para a proteção dos direitos difusos. [...] A visão individualista do devido processo judicial está cedendo lugar rapidamente, ou melhor, está se fundindo com uma concepção social, coletiva [...] Mecanismos tais como os que já discutimos para a proteção dos interesses difusos são especialmente apropriados para a abordagem desses problemas. Alguns mecanismos, como a "class action", podem ser utilizados tanto para dar amparo aos indivíduos, quanto para impor os direitos coletivos duma classe [...] $\mathrm{O}$ enfoque de acesso à Justiça pretende levar em conta todos esses fatores. Há um crescente reconhecimento da utilidade e mesmo da necessidade de tal enfoque no mundo atual" (CAPPELLETTI; GARTH, Bryan.1988. p. 31/49-51/67-73).

2 Após a Emenda Constitucional $\mathrm{n}^{\circ}$ 80, a CF/88 passou a considerar expressamente a Defensoria como uma instituição permanente, fortalecendo as funções institucionais e acrescentando no Carta Magna a defesa dos coletivos.
}

Revista de Direito Brasileira | São Paulo, SP | v. 15 | n. 6 | p. 337 - 353 | set./dez. 2016 
instituição em relação aos direitos coletivos (a propósito, justamente entorno deste aspecto que se insere o objeto de estudo do presente trabalho).

Impossível, pois, falar do acesso à justiça e não relacionar este tema com a atuação das Defensorias Públicas, visto que, conforme dito alhures, tal instituição é constitucionalmente considerada como essencial para a justiça, tendo em vista a sua relevância democrática, pois visa proporcionar o acesso à justiça de forma ampla e igualitária para os indivíduos. De acordo com Cappelletti e Garth (2002), o acesso à justiça deve:

[...] ser encarado como o requisito fundamental - o mais básico dos direitos humanos - de um sistema jurídico moderno e igualitário que pretenda garantir, e não apenas proclamar os direitos de todos. (CAPPELLETTI; GARTH, 2002. p. 12)

Os mencionados doutrinadores italianos sustentaram a existência de três "ondas renovatórias"3 que expressam a evolução do acesso à justiça, sendo caracterizadas pela: 1) assistência judiciária para os pobres; 2) representação dos interesses difusos; e 3) efetividade dos mecanismos de acesso à justiça.

Hodiernamente, é cada vez mais premente que se fomente "o debate sobre o conteúdo e o significado contemporâneo do acesso à justiça entre nós, antes que soçobre de vez a estrutura judiciária do país" (MANCUSO, 2015, p. 216), tendo em vista a morosidade bem como a emergência de fenômenos processuais ${ }^{4}$, que são verdadeiros entraves ao acesso à justiça, razão pela qual é crucial ressaltar que:

[...] o direito de acesso à justiça possui duas facetas: a primeira é a faceta formal, e consiste no reconhecimento do direito de acionar o Pode Judiciário. A segunda faceta é a material ou substancial, e consiste na efetivação desse direito: (i) por meio do reconhecimento da assistência jurídica integral e gratuita aos que comprovem a insuficiência de recursos (art. $5^{\circ}$, LXXIV); (ii) pela estruturação da Defensoria Pública como instituição essencial à função jurisdicional do Estado (art. 134); (iii) pela aceitação da tutela coletiva dos direitos e da tutela de direitos coletivos, que possibilita o acesso à justiça de várias demandas reprimidas; e (iv) pela insurgência de um devido processo legal em prazo razoável, pois não basta possibilitar o acesso à justiça em um ambiente judicial marcado pela morosidade e delonga. (RAMOS, 2015, p. 596)

A criação e estruturação de instituições estatais com tal objetivo constitucional, como as Defensoria Públicas, sem dúvida, foi um importante avanço para a concretização do acesso à justiça. (FENSTERSEIFER,2015, p. 54-55), tendo em vista a natureza prestacional, onde o Estado passou a ter o dever de criar e estruturar órgãos judiciários e processos adequados para que sejam asseguradas prestações tendentes a evitar a denegação da justiça por ausência ou até mesmo insuficiência de meios econômicos e/ou estruturais (CANOTILHO, 2003, p. 498-501).

Em relação à aceitação da tutela coletiva, tem-se como avanço o fortalecimento de instrumentos e práticas criados e aperfeiçoados com tal propósito, destacando-se, nesse sentido, a

\footnotetext{
${ }^{3}$ Basicamente, o estudo elaborado por Cappelletti e Barth se fundamentou na criação de 'ondas renovadoras', diante dos desafios para a concretização de direitos, pois: "We have characterized the access-to-justice movement as involving "waves" of reform aimed at the challenging problem of making rights effective".(destacou-se) GARTH;CAPPELLETTI 1981, p. X).

${ }^{4}$ Um exemplo de fenômeno processual emergente é assédio processual, que consiste, em ser "um conjunto de condutas antijurídicas praticadas no curso de um processo judicial por uma parte litigante, com o propósito de evitar que a outra parte veja-se contemplada no resultado pretendido, isto é, no recebimento da tutela jurisdicional efetiva" (GENEHR, 2015, p.152)
} 
elaboração de um Código de Processo Coletivo ${ }^{5}$ para dar uniformidade e sistematicidade normativa à tutela coletiva (GRINOVER; MENDES, WATANABE,2007).

Conforme já mencionado, além da importância da Defensoria para a efetivação dos direitos individuais e coletivos, como um órgão essencial ao Estado democrático de direito, temse que cabe à Defensoria, a priori, a amplitude de defesa, devidamente digna e justa dos hipossuficientes, proporcionando-lhes um legítimo acesso à justiça fundamentado por um sistema jurídico:

[...] pelo qual pessoas podem reivindicar seus direitos e/ou resolver seus litígios sob os auspícios do Estado. Primeiramente, o sistema deve ser igualmente acessível a todos; segundo, ele deve produzir resultados que sejam individual e socialmente justos [...] (CAPPELLETTI; GARTH, 2002. p.8).

Destaca-se, portanto, que o poder judiciário, dentre os demais poderes constitucionalmente estabelecidos, é o mais importante protetor dos direitos fundamentais, da liberdade e do exercício da cidadania ${ }^{6}$.

Para a segurança de acesso a um ordenamento jurídico justo, garantindo a efetividade do processo (CANOTILHO, 2003, p. 491-494), devem ser analisados alguns pontos sensíveis, como por exemplo: admissão do processo (nesse caso, engloba-se a atuação da defesa de direitos coletivos ou difusos); modo de ser do processo (garantia do devido processo legal); e, por fim a justiça e utilidade nas decisões (CINTRA; GRINOVER; DINAMARCO,1999,p.33-35) para se chegar à almejada eliminação dos conflitos e a realização de justiça, possibilitando, assim, um verdadeiro acesso à justiça, visto que de nada adianta a existência meramente formal de um processo que não atenda às necessidades sociais. $O$ acesso à justiça, portanto, deve ser proporcionado de maneira que possibilite a concretização do devido processo legal, conforme mencionado alhures, bem como dos demais princípios constitucionais que garantam a segurança do ordenamento jurídico. Nesse sentido, tem-se que:

[...] ao assegurar o direito fundamental de defesa dos direitos e interesses protegidos pelo ordenamento jurídico, o direito ao acesso à justiça impõe um dever de proteção ao Estado por meio de normas que garantam a abertura da via judiciária. Além disso, os caminhos a serem percorridos pelo jurisdicionado em tal via devem ser adequados, sob pena de ineficácia da proteção constitucional. (FERRAZ, 2013)

Nesse diapasão, observa-se que o acesso à justiça, evidente corolário do duo process of $l a w^{7}$, integra um conjunto de princípios constitucionais que norteiam o Estado de Direito (CANOTILHO, 2003, p.230).

\footnotetext{
${ }^{5}$ Deriva, sem dúvida, da ideia de um código-modelo de processos coletivos para Ibero-América, cujo escopo primordial é orientar a legislação dos países ibero-americanos. Não é despiciendo mencionar que a legitimidade, no anteprojeto deste código já era ampla, ou seja, já incluía a Defensoria Pública, por meio do art. $3^{\circ}$, inc. III, no rol dos legitimados para garantirem à tutela dos direitos difusos. Acrescenta-se, ainda, que "[...] las tendencias que prevalecen entre los cultivadores del derecho procesal civil em la segunda mitad del siglo XX, es la utilización, cada vez más difundida, de los métodos de análisis del derecho comparado.(..) El análisis comparativo del proceso civil, sobre todo cuando se le emplea como instrumento de política del derecho, contribuye a la elaboración de proyéctos legislativos para países que, como los iberoamericanos, tienen una tradición común.”[...] (FAVELA, 2001, p.32).

${ }^{6}$ Não é despiciendo reforçar que o acesso à justiça somente conquista real efetivação na medida em que há o fortalecimento de instituições essenciais à justiça. Nesse sentido, se faz necessário a valorização e o real fortalecimento da instrumentalização dos direitos coletivos, possibilitando efetivos mecanismos de atuação desses órgãos essenciais, haja vista que "[...] la tendencia a hacer efectivo acceso a la justicia la asumido mayor importância en el derecho procesal civil y es una de las caracteristicas fundamentales del Estado social de derecho" (FAVELA, 2001, p. 30-31).
} 
Ao se deparar com a análise do acesso à justiça na seara coletiva, através da atuação institucional da Defensoria Pública, alguns aspectos problemáticos emergem-se na realidade processual, dentre eles: a) A delimitação da interpretação da terminologia "hipossuficiência" estabelecida no art.134 da CF/88 b) A estrutura física, ainda precária, de algumas Defensorias Públicas (realidade que interfere gravemente na concretização dos direitos individuais e coletivos, e, muita das vezes, acaba se tornando óbice para o acesso à justiça).

Em relação à interpretação conferida à terminologia: "necessitados", nota-se que não deve ser compreendida de maneira restritiva aos conceitos de "necessidade" e "insuficiência de recursos", tendo em vista que, caso assim fosse, se configuraria como um risco limitar a atuação da Defensoria Pública ao se levar em consideração exclusivamente à hipossuficiência econômica, pois tal redução afronta a própria natureza jurídica dos direitos difusos, tendo em vista a ausência de individualização dos tutelados, conforme será detalhado no decorrer deste trabalho.

A problemática relacionada à estrutura institucional ${ }^{8}$ precária das Defensorias Públicas, ainda é possivelmente umas das consequências relacionadas ao recente processo de democratização do ordenamento e traz uma série de fatores que limitam a atuação institucional deste órgão essencial à justiça, realidade que desafia a democratização do acesso à justiça.

Em respeito à análise da estrutura funcional, em âmbito sergipano, constatou-se que a atuação da Defensoria Pública do Estado de Sergipe não possui nenhum núcleo de proteção específico e estruturado para as ações civis públicas (o que há, até o presente momento, é a divisão de núcleos gerais (como por exemplo: núcleo de bairros; saúde; consumidor; direitos humanos, etc.), ou seja, a Defensoria no Estado de Sergipe propõe as ações coletivas, presta este substancial serviço para a coletividade, porém ainda não possui um controle sistematizado das ações civis públicas propostas, não havendo consequentemente, de maneira precisa, dados relacionados a tal temática.

Tendo como parâmetro norteador a realidade organizacional da Defensoria do Estado de Manaus $^{9}$ e da Defensoria Pública do Estado do Tocantins ${ }^{10}$, pode-se afirmar que seria viável a construção de núcleos especializados para as ações coletivas propostas em âmbito sergipano.

A construção de tais núcleos especializados transcende a mera questão de organização interna das Defensorias Públicas, visto que proporciona congregar estudos e pesquisas acerca da atuação nas mencionadas causas coletivas, além de, obviamente, proporcionar a orientação dos próprios defensores públicos para o entendimento institucional acerca das teses adotadas no que tange, notadamente, à tutela dos direitos coletivos e difusos, fomentando, por conseguinte, a atualização profissional (que é necessária, considerando-se a evolução dos direitos transindividuais, fruto da dinamicidade das ciências jurídicas).

É imprescindível, portanto, em relação à proteção dos direitos difusos e coletivos realizada pelas Defensorias Públicas, uma reforma, tanto no aspecto exegético no tocante à terminologia "hipossuficiência", que permita ampliar a atuação funcional, quanto no cenário

\footnotetext{
${ }^{7} \mathrm{O}$ devido processo legal, instituto jurídico inserido no ordenamento brasileiro por meio de notória influência da Constituição norte-americana, "objetiva a sedimentação da justiça de ordem processual, procedimental e com a conformação justa e adequada do direito à tutela jurisdicional" (FERRAZ, 2013).

${ }^{8}$ A necessidade de fortalecimento institucional vem sendo reconhecida pelo Poder Legislativo, (vide: proposta de Emenda à Constituição $\mathrm{n}^{\circ}$ 247, de 2013, da relatoria do Dep. Amauri Teixeira, mesmo após a neoconstitucionalização ainda hoje a instituição "Defensoria Pública" não está instalada em todos os Estados da Federação. Em alguns casos, sequer o primeiro concurso público para o cargo de defensor público foi iniciado ou concluído" (BRASIL, 2013). Essa realidade é corroborada pelos dados fixados no Mapa da Defensoria Pública no Brasil (IPEA, 2013, n.p), elaborado pelo Instituto de Pesquisa Econômica Aplicada (IPEA) e a ANADEP Associação Nacional de Defensores Públicos.

${ }^{9} \mathrm{Na}$ relação dos núcleos especializados da Defensoria Pública do Estado de Manaus, encontra-se o núcleo Defensoria Pública especializada em ações coletivas, que atende as questões de interesse de coletividades.

${ }^{10}$ No Estado do Tocantins, a atuação da Defensoria pública, é verificada por meio do "'NAC' - Núcleo Especializado de Direitos Difusos, Coletivos e Individuais Homogêneos ou Núcleo de Ações Coletivas" (DEFENSORIA PÚBLICA DO ESTADO DO TOCANTINS,2016, n.p).
} 
estrutural da instituição, para que se possa, efetivamente, possibilitar o acesso à justiça de forma igualitária e concreta, e não meramente formal.

\section{A LEGITIMIDADE DA DEFENSORIA PÚBLICA PARA PROPOR AÇÕES CIVIS PÚBLICAS: EFETIVAÇÃO DA DEMOCRATIZAÇÃO DO ACESSO À JUSTIÇA E A CONCRETIZAÇÃO DOS DIREITOS FUNDAMENTAIS}

Os direitos coletivos e difusos, considerados direitos fundamentais de terceira geração ou dimensão, são consequência de reivindicações do ser humano, na medida em que baseiam-se na busca pela proteção de agrupamentos humanos (evidenciando-se assim, a natureza coletiva ou difusa). $\mathrm{O}$ advento desta geração acarretou significativos reflexos tanto no cenário dos direitos fundamentais quanto na realidade procedimental acerca dos mecanismos processuais de proteção aos direitos fundamentais. (SARLET, 2012, 48-50).

O processo coletivo é caracterizado quando ocorre a busca pela tutela jurisdicional de um interesse metaindividual ${ }^{11}$ (seja ele direito difuso, coletivo em sentido estrito, individual homogêneo, previsto no art. 81 da Lei. 8.078/90)(MANCUSO, 2006, p.58-59).

Em relação à legitimidade processual ativa, a doutrina reconhece que "uma das mais complexas questões, no que diz respeito às ações coletivas, refere-se à legitimidade para a causa"(MARINONI; MITIDIERO; ARENHART, 2015, p.415), pois apesar de parecer mais sensato a afirmação de que tal legitimidade seja considerada extraordinária, até pelo fato da impraticável hipótese dos lesados comparecerem em juízo, "nem todos os estudiosos, porém reconhecem que se trata de legitimação extraordinária aquela que se encontra no polo ativo das ações civis públicas ou coletivas" (MANCUSO, 2015, p. 65)

Essa dificuldade paira acerca da diferença entre o instituto da legitimidade ativa em seara individual e coletiva, visto que, apesar da legitimidade ativa constituir-se numa condição para a ação processual, nos termos do art. 17 do NCPC, é mister destacar que a "legitimação para agir, com todas as suas implicações, não deve ter a mesma aplicação ao processo coletivo como tem no processo civil comum, individualista" (VERRI, 2008, p.37). Por essa razão, além da existência da presunção de legitimidade ad causam ativa, no processo coletivo, parte-se da premissa da possibilidade do acesso à justiça à grande quantidade de titulares de direitos, ora determinados ora indetermináveis.

A principiologia, no processo coletivo ${ }^{12}$, pode ser dividida com base na classificação entre princípios constitucionais, dentre eles: o Princípio do interesse jurisdicional no conhecimento do mérito do processo coletivo; Princípio da máxima prioridade jurisdicional da tutela jurisdicional coletiva; e o Princípio da presunção da legitimidade ad causam ativa nas demandas coletivas (VERRI, 2008, p.57-60).

Em relação ao princípio do interesse jurisdicional no conhecimento do mérito do processo coletivo, verifica-se que o seu fundamento ${ }^{13}$ se encontra no artigo $5^{\circ}, \mathrm{XXXV}$, cumulado com os art. $1^{\circ}$ e $3^{\circ}$, ambos da Constituição Federal, visto que as partes tem o direito de obter do

\footnotetext{
${ }^{11}$ Interessante destacar que vigora, na seara coletiva, a noção de "não-taxatividade" em relação ao objeto da ação coletiva, conforme a previsão dos arts. 5, XXXV e 129, III, ambos da Constituição Federal, cujo entendimento norteia a aplicabilidade do art. $1^{\circ}$, IV, da 7.347/85.

${ }^{12} \mathrm{O}$ sistema brasileiro tem clara influência do sistema anglo-americano, haja vista a inspiração das class actions for damages, com o escopo de proporcionar a denominada: representação adequada. (MARINONI; MITIDIERO; ARENHART, 2015, p.415)

13 Pode-se verificar, também, que o mencionado princípio está devidamente fundamentado, em âmbito infraconstitucional, nos arts. $4^{\circ}$ e 139 , inc. IX do NCPC/2015, visto que garante ao jurisdicionado a efetivação do princípio da primazia da decisão de mérito. Logo, o julgado não deve extinguir o processo por mera ausência falta de requisito processual.
} 
judiciário a solução integral do mérito, e para isto, o Poder Judiciário deve enfrentar o mérito das ações coletivas, sob a égide dos fundamentos do Estado democrático de direito.

No tocante ao princípio da máxima prioridade jurisdicional da tutela jurisdicional coletiva, cujo fundamento se materializa no artigo $5^{\circ}, \S 1^{\circ}, \mathrm{CF}$, entende-se que o processo coletivo deve ser analisado com a máxima prioridade, haja vista o interesse social inserido numa demanda coletiva.

O princípio da presunção da legitimidade ad causam ativa ${ }^{14}$ possui fundamento ${ }^{15}$ legal nos artigos 127, caput; 129, III e $\$ 1^{\circ}$, da Constituição Federal.

Diante disso, verifica-se que a efetivação da democratização do acesso à justiça e a concretização dos direitos fundamentais conquistam cada vez mais espaço no ordenamento jurídico brasileiro, partindo-se da premissa que, hodiernamente, os direitos coletivos e difusos almejam crescente força, após terem sido inseridos no rol dos direitos fundamentais consagrados na $\mathrm{CF} / 88$.

Acontece que tal previsão legal vem sendo cada vez mais instrumentalizada por meio de medidas processuais cabíveis, como é o caso da ação civil pública, pois:

[...] o uso da ação civil pública tem se revelado um magnífico instrumento de educação social e democrática [...]. A ação civil pública transformou-se desse modo em instituto de solução judicial e pacífica dos conflitos qualificados pela presença dos interesses difusos e coletivos. Poucos percebem esse lado da ação civil pública, notável e digno de registro (BURLE FILHO, 2001, p.362-364)

Com isso, nota-se que ocorreu, recentemente, um aumento quantitativo dos legitimados para a sua propositura, fato que possibilitou o franqueamento da legitimidade atribuída ao Ministério Público, ao devidos co-legitimados expressos, conforme o art. $129, \S 1^{\circ}$, CF. Frise-se: louvável tal amplitude, visto que a atuação do Parquet, em sede de ação civil pública, não é exclusiva $^{16}$, não obstante a inserção de outros legitimados não substituir a atuação do Ministério Público, uma vez que a propositura de ação civil pública continua sendo uma das funções institucionais do Órgão Ministerial, nos termos do inciso III do art. 129, CF, razão pela qual se consubstancia a democratização do acesso à justiça.

Seguindo esse raciocínio de garantir o acesso à justiça de forma ampla e com a pretensão de concretizar os direitos fundamentais, nos termos da Lei 11.448/07, ocorreu a alteração do art. $5^{\circ}$, inc.II da Lei da Lei $\mathrm{n}^{\mathrm{o}} 7.347 / 1985$, ampliando o rol de legitimados para a propositura ${ }^{17}$, com o fundamento de que "[...] na ordem jurídica não há preferência alguma entre os diversos legitimados" (THEODORO JÚNIOR, 2016, p. 738).

\footnotetext{
${ }^{14}$ Em respeito à legitimidade ativa no processo civil coletivo, principalmente no que tange o princípio da presunção da legitimidade, observa-se que tal debate ainda é polêmico, pois existem processualistas que defendem a existência da tese de legitimidade extraordinária. "Outros fundamentam ser legitimidade extraordinária na modalidade substituição processual. Ademais, existem ainda aqueles que ignoram a legitimidade extraordinária, fundamentando que essa só existe no direito processual civil individual, e, portanto, defendem outras classificações, ou seja, próprias do sistema processual coletivo"(VERRI, 2008, p.39-40).

${ }^{15}$ Este princípio também esta claramente previsto infraconstitucionalmente tanto no art. 82 da Lei 8078/90, quanto no rol trazido pelo art. $5^{\circ}$ da Lei $7.347 / 85$.

16 Suposta teoria de exclusividade do Parquet para propor ação civil pública não merece respaldo no atual ordenamento constitucional brasileiro, pois consiste em ser "da essência da legitimação do MP, no campo da ação civil pública, que sua iniciativa não seja exclusiva, mas concorrente. Assim, enquanto detém o monopólio da ação penal privada subsidiária, em caso de inércia sua legitimação para ações civis públicas não exclui a de terceiros, como, aliás, o assegurara a CR (art.129, § $1^{\circ}$ )" (MAZZILLI, 1992, ano 40).

${ }^{17}$ A título de detalhamento, evidencia-se que a regulamentação legal para a atuação da Defensoria Pública ao tutelar os direitos difusos e coletivos, por meio de ação civil pública, tem como fundamentado direito o art. $5^{\circ}$, inciso II, da Lei $7.347 / 85$.
} 
Acontece que "a consagração legislativa de um direito é apenas o primeiro passo rumo a sua efetivação no plano concreto" (FENSTERSEIFER,2015, 72). Ou seja, embora já exista, desde o ano de 2007 (dois mil e sete), a previsão legal de atuação da Defensoria Pública para proposição de ação civil pública na defesa da coletividade, o conteúdo, até o final ano de $2015^{18}$ (dois mil e quinze) era polêmico no cenário jurídico atual. Mas o fato é que a Defensoria Pública vinha impetrando ações civis públicas na defesa dos direitos coletivos e difusos, mesmo antes da Lei 11.448/07, com fulcro nos art. 81 e 82 do CDC.

Conforme já mencionado, o número de ações civis públicas propostas pela Defensoria Pública cresceu progressivamente, com o advento da nova concepção de direitos coletivos. Com isso, nota-se que surgiu uma relevante divergência doutrinária acerca dessa legitimidade, com o embasamento de que dever-se-ia ocorrer uma interpretação restritiva do conceito de "necessitado" à luz dos art. 134 e art.5 $5^{\circ}$ LXXIV, da CF, que determinam que a função institucional está condicionada à necessidade social.

Ora, a argumentação jurídica mencionada para afastar a atuação da Defensoria Pública na defesa dos direitos coletivos e difusos, por meio de ação civil pública, não se sustenta, visto que o "estado de necessidade", para ser caracterizado, faz-se necessário que haja a identificação dos tutelados, ou seja, é primordial que, pelo menos, os merecedores da proteção jurídica, sejam identificados ou identificáveis. Nesse contexto, atuação da Defensoria Pública nos interesses difusos, seria inviável, pois estes direitos:

[...] são interesses ou direitos 'transindividuais, de natureza indivisível, de que sejam titulares pessoas indeterminadas e ligadas por circunstância de fato’. Os interesses difusos compreendem grupos menos determinados de pessoas(melhor do que indeterminadas, são antes pessoas indetermináveis), entre as quais inexiste vinculo jurídico ou fático preciso. São como um feixo ou conjunto de interesses individuais, de objeto indivisivel, compartilhados por pessoas indetermináveis, que se encontram unidas por circunstâncias de fato conexas.(MAZZILLI, 2015, p.53)

Diante da impossibilidade de discriminação do rol de tutelados ${ }^{19}$, observa-se que a defesa da legitimidade da Defensoria transcende ${ }^{20}$ a delimitação da terminologia "hipossuficiência", tendo em vista que seu objetivo é viabilizar o acesso à justiça, possibilitando nítida economia processual, ao fomentar a redução da proliferação demasiada de ações individuais.

Portanto, a atuação da Defensoria, na seara coletiva, não deve ser limitada à interpretação restritiva do conceito de hipossuficiência, sob pena de obstacularizar o acesso ao Judiciário. Neste sentido, entende o Tribunal da Cidadania. ${ }^{21}$

\footnotetext{
${ }^{18}$ A mencionada polêmica fora devidamente estabilizada no mundo jurídico, através do recente posicionamento do STF, por meio da ADI 3943, conforme será detalhado no decorrer deste trabalho.

19 MINAS GERAIS. Tribunal de Justiça. Apelação Cível. Processo $n^{o}$ 1.0024.09.701231-4/001. julgado em: 17/05/2011. Comarca de Belo Horizonte. $7^{\mathrm{a}}$ CÂMARA CÍVEL. Apelante: Defensoria Pública Estado Minas Gerais Apelado(A)(S): Município Belo Horizonte - Relator: Exmo. Sr. Des. Belizário De Lacerda.

${ }^{20}$ Seguindo essa lógica jurídica, MANCUSO (2009) destaca o voto da Ministra do STJ, Fátima Nancy Andrighi, no julgamento do RESp 555.111 (rel. Min. Castro Filho, j.05.05.2006, DJ 18.12.2006) e afirma que: [...] se propugnou por uma interpretação atualizada e contextualizada da expressão 'necessitado', contida na vetusta Lei 1.060/50: '[...] não é pelo fato de os consumidores terem adquirido automóveis que não podem ser considerados necessitados para fins do art. 134 da CF; porquanto o conceito jurídico de necessitado, contido no parágrafo único do art. $2^{\circ}$ da Lei 1.060/50, é mais amplo do que ser 'pobre' ou 'miserável', não está vinculado a determinado limite de valor de renda mensal ou de patrimônio e, sim, à impossibilidade de pagamento das despesas processuais em prejuízo do próprio sustento ou da família'. (MANCUSO, 2009, p. 146).

${ }^{21} \mathrm{AgRg}$ no AREsp 67.205/RS, Rel. Ministro BENEDITO GONÇALVES, PRIMEIRA TURMA, julgado em 01/04/2014, DJe 11/04/2014.
} 
A celeuma jurídica que se instalou, basicamente, foi acerca da existência, ou não, da legitimidade da Defensoria em casos onde tutelados economicamente abastados também sejam beneficiados com ações coletivas. ${ }^{22}$

Ora, indiscutivelmente, a principal função institucional da Defensoria Pública é a orientação jurídica e a defesa dos necessitados, haja vista a grande demanda desse tipo de atuação no processo individual. Contudo, em relação às demandas que envolvem titulares indeterminados ou indetermináveis - como é o nítido caso de proteção dos direitos difusos -, dentre estes tutelados, certamente, haverá um grupo de sujeitos necessitados. O que não se pode é restringir o conceito de necessidade, tendo em vista as múltiplas variações de estado de necessidade que o ser humano possui no âmbito jurídico, sob a pena de se reduzir a atuação institucional desta relevante instituição, que é essencial para o acesso à justiça e para o protagonismo da judicialização e do ativismo judicial, juntamente com o Ministério Público, nos termos da legitimação concorrente e disjuntiva estabelecida no art. $5^{\circ}$ da Lei 7.347/85.

Nesse diapasão, sustenta-se que a hipossuficiência, pertinência temática de atuação (na tutela individual) da Defensoria Pública, em sede de demandas coletivas, não deve apenas se limitar a escassez de recursos financeiros, devendo-se abranger também outras formas de necessidades, como por exemplo: organizacional e jurídica, tendo em vista que:

[...] nem sempre o conceito de "insuficiência" pode ser definido a priori. $\mathrm{O}$ caso, a situação jurídica concreta, especialmente quando se trate de defesa em juízo, é que vão indicar se o interessado está ou não em condições de organizar a defesa de seus direitos por conta própria. Não é necessário que o interessado seja absolutamente desprovido de recursos, seja miserável" (SILVA, 2008. p. 173)

A discussão que se instaura deve se concentrar na reflexão sobre a extensão dos efeitos da atuação do legitimado ativo para propositura da ação e não exclusivamente na delimitação dos titulares deste referido instrumento processual, pois, conforme já destacado, em direitos difusos, há a indeterminação dos titulares. Com isso, constata-se que o mero fato de não se identificar o rol de tutelados, não significa a ausência de interesse dos hipossuficientes, dado que, possivelmente haverá a real necessidade da proteção processual e material desta coletividade.

$\mathrm{O}$ fato é que a legitimidade não pode ser afastada de imediato, sob o fundamento de não se poder determinar os beneficiados da prestação jurisdicional. À luz de se conquistar a integralidade da prestação jurisdicional, considera-se que o conceito de "necessidade" trazido pela Carta Magna, apresenta a possibilidade de ser interpretado de forma ampla ${ }^{23}$, fortalecendo institucionalmente a Defensoria Pública.

Nesse sentido, por meio do estudo do direito comparado, pode-se concluir que a solução para a representação nas ações coletivas é garantida pela adequacy of representation ${ }^{24}$, na medida em que possibilita o controle jurisdicional da legitimidade coletiva de acordo com as nuances e as necessidades de cada caso concreto. Na realidade forense brasileira seria a demonstração do nexo causal entre a demanda e a presença de titulares em estado de hipossuficiência, podendo ser

\footnotetext{
${ }^{22}$ Do mesmo modo é o entendimento do Tribunal da Cidadania (STJ) no REsp 1192577/RS, Rel. Ministro LUIS FELIPE SALOMÃO, QUARTA TURMA, julgado em 15/05/2014, DJe 15/08/2014.

${ }^{23}$ Haja vista que necessitado jurídico consiste em ser "mais uma faceta da assistência jurídica, assistência a necessitados, não no sentido econômico, mas no sentido de que o Estado lhes deve as garantias do contraditório e da ampla defesa" (GRINOVER,1990, p.246)

${ }^{24}$ A adequacy of representation, (tradução nossa: A adequação do representante ou adequação da representação) é um dos requisitos de admissão das ações coletivas (class action) nos EUA, vinculado ao devido processo legal. Encontra-se previsto na Regra 23, "a" das Federal Rules of Civil Produre, novel legal que regula o processo civil americano, no âmbito federal. (WOOLLEY, 1997, p. 571.) e (BONE, 1992, p. 214).
}

Revista de Direito Brasileira | São Paulo, SP | v. 15 | n. 6 | p. 337 - 353 | set./dez. 2016 
financeiro, organizacional ${ }^{25}$ ou até mesmo tecnicamente jurídico. Nessa linha de raciocínio, temse que:

[...] existem os que são necessitados no plano econômico, mas também existem os necessitados do ponto de vista organizacional. Ou seja, todos aqueles que são socialmente vulneráveis: os consumidores, os usuários de serviços públicos, os usuários de planos de saúde, os que queiram implementar ou contestar políticas públicas, como as atinentes a saúde, a moradia, ao saneamento básico, ao meio ambiente etc."(destacou-se) (GRINOVER, 2011, p. 483.)

Diante disso, questiona-se: A Defensoria Púbica está legitimada, de forma ampla, para tutelar, em juízo, qualquer direito coletivo em favor de qualquer grupo, ou, em contrário senso, a legitimidade ativa conferida a esta relevante instituição essencial à justiça estaria limitada à defesa dos direitos coletivos das pessoas necessitadas ${ }^{26}$ ? Com o escopo de pacificar, definitivamente, tal divergência jurisprudencial, o Supremo Tribunal Federal delimitou posicionamento, através do julgamento da Ação Direta de Inconstitucionalidade $n^{\circ} 3.943$.

\section{POSICIONAMENTO DO SUPREMO TRIBUNAL FEDERAL ACERCA DA LEGITIMIDADE ATIVA DA DEFENSORIA PÚBLICA NA DEFESA DE DIREITOS DIFUSOS E COLETIVOS: ANÁLISE DA ADI 3.943}

Conforme visto, a polêmica doutrinária acerca dos limites para a legitimidade ativa da Defensoria Pública ganhou força, a ponto de fomentar a interposição de uma Ação Direta de Inconstitucionalidade - ADI nº 3.943, cuja titularidade pertenceu à Associação Nacional dos Membros do Ministério Público - CONAMP. Nessa referida ação, basicamente, buscou-se o confrontamento das teses divergentes, pois teve como objeto a Lei da Ação Civil Pública, de maneira particular, destinou a análise do art. $5^{\circ}$ da Lei 7.347/85, que expressamente incluiu a Defensoria Pública no rol dos entes que possuem legitimidade para propor a ação civil pública. Trata-se de nítido dissenso de natureza constitucional processual.

Os argumentos giram em torno da alegação de que a legitimidade ativa, na defesa de direitos difusos e coletivos, contrariaria o art. $5^{\circ}$, inc. LXXIV, e o art.134, ambos da Constituição da República, havendo, pois, um vício material de inconstitucionalidade, asseverando que a Defensoria não teria competência para defender interesses da coletividade, haja vista que somente teria titularidade para atuar na defesa dos necessitados hipossuficientes de recursos financeiros. Com isso, em resumo, o CONAMP procurou restringir à legitimidade da defesa aos direitos coletivos e individuais homogêneos.

A discussão jurídica foi fomentada com a aprovação da emenda constitucional $n^{\circ}$ 80/2014, visto que a Defensoria passou a ter expressamente como competência institucional a defesa dos direitos coletivos. Diante disso, foi trazida ao processo uma tese relacionada à suposta alegação de constitucionalização superveniente, fundamento este que não mereceu prosperar, com razão a tese adotada pelo Supremo Tribunal Federal (STF), uma vez que a norma objeto de

\footnotetext{
${ }^{25}$ Nesse sentido, observa-se que a Defensoria tem como uma das funções institucionais “[...] exercer a defesa dos interesses individuais e coletivos da criança e do adolescente, do idoso, da pessoa portadora de necessidades especiais, da mulher vítima de violência doméstica e familiar e de outros grupos sociais vulneráveis que mereçam proteção especial do Estado" (art. 4, XI, da LC n. 80/94, com as alterações trazidas pela LC nº 132/2009. Há, ainda, nessa mesma lei, a previsão de proteção ao consumidor, ao adolescente, dentre outros.

${ }^{26}$ A interpretação restrita com base na antiga redação do art. 134 da $\mathrm{CF}$ (alterada após a Emenda Constitucional $\mathrm{n}^{\circ}$ 80/2014), afastaria, consequentemente, a atuação na proteção dos direitos difusos. Sendo reduzida a legitimidade da Defensoria Pública à defesa dos interesses coletivos e individuais homogêneos, não abarcando, portanto, os interesses difusos (MANCUSO, 2011, p.157).
} 
análise inicial da ADIn 3.943 já era constitucional, por esse motivo o pleito de perda do objeto da ação fora indeferido e a ação foi julgada em seu mérito.

Nítido foi o entendimento do STF acerca do fortalecimento da democratização do acesso à justiça, e, para isso, fez-se necessário o reconhecimento a evolução ${ }^{27}$ da processualística brasileira, visto que:

[...] as modificações do sistema processual civil operaram-se em duas fases, ou "ondas", bem distintas. Uma primeira onda de reformas, iniciada em 1985, foi caracterizada pela introdução, no sistema, de instrumentos até então desconhecidos do direito positivo, destinados (a) a dar curso a demandas de natureza coletiva, (b) a tutelar direitos e interesses transindividuais, e (c) a tutelar, com mais amplitude, a própria ordem jurídica abstratamente considerada. E a segunda onda reformadora, que se desencadeou a partir de 1994, teve por objetivo não o de introduzir novos, mas o de aperfeiçoar ou de ampliar os já existentes no Código de processo, de modo a adaptá-lo às exigências dos novos tempos[...] (ZAVASCKI, 2014. p. 14-15).

O Supremo Tribunal Federal (STF), por unanimidade de votos, com força na doutrina e jurisprudência contemporâneas, em respeito às normas fundamentais, norteou o seu posicionamento à luz da democratização do acesso à justiça e da concretização dos direitos fundamentais $^{28}$, colocando uma "pá de cal" na temática, para neutralizar e afastar definitivamente o suposto dilema jurídico que ainda reinava na interpretação de muitos juristas, na medida em que conferiu a manutenção da legitimidade da Defensoria Pública para atuar em tais ações coletivas, nos termos da seguinte ementa:

AÇÃO DIRETA DE INCONSTITUCIONALIDADE. LEGITIMIDADE ATIVA DA DEFENSORIA PÚBLICA PARA AJUIZAR AÇÃO CIVIL PÚBLICA (ART. 5\%, INC. II, DA LEI N. 7.347/1985, ALTERADO PELO ART. $2^{\circ}$ DA LEI N. 11.448/2007). TUTELA DE INTERESSES TRANSINDIVIDUAIS (COLETIVOS STRITO SENSU E DIFUSOS) E INDIVIDUAIS HOMOGÊNEOS. DEFENSORIA PÚBLICA: INSTITUIÇÃO ESSENCIAL À FUNÇÃO JURISDICIONAL. ACESSO À JUSTIÇA. NECESSITADO: DEFINIÇÃO SEGUNDO PRINCÍPIOS HERMENÊUTICOS GARANTIDORES DA FORÇA NORMATIVA DA CONSTITUIÇÃO E DA MÁXIMA EFETIVIDADE DAS NORMAS CONSTITUCIONAIS: ART. $5^{\circ}$, INCS. XXXV, LXXIV, LXXVIII, DA CONSTITUIÇÃO DA REPÚBLICA. INEXISTÊNCIA DE NORMA DE EXCLUSIVIDADE DO MINISTÉRIO PÚBLICO PARA AJUIZAMENTO DE AÇÃO CIVIL PÚBLICA. AUSÊNCIA DE PREJUÍZO INSTITUCIONAL DO MINISTÉRIO PÚBLICO PELO RECONHECIMENTO DA LEGITIMIDADE DA DEFENSORIA PÚBLICA. AÇÃO JULGADA IMPROCEDENTE. (STF, ADI 3943, Rel. Min. CÁRMEN LÚCIA, Tribunal Pleno, j. 7/5/2015, ACÓRDÃO ELETRÔNICO DJe-154, div. 5-8-2015 p. 6-8-2015).(destacamos)

\footnotetext{
${ }^{27}$ Nesse sentido: “A ampliação da tutela jurisdicional, para introduzir as autênticas ações coletivas, ou de grupo, no direito processual pátrio, ocorreu com a instituição da ação civil pública por meio da Lei Complementar n. 40, de 13.12.81, e Lei n. 7.347, de 27.07.85" (THEODORO JÚNIOR, 2016, p. 732).

${ }^{28}$ Importante destacar que o Tribunal da Cidadania - STJ, após o longo dissenso jurisprudencial, se posicionou de maneira favorável a este raciocício juridico: “[...] 2. O entendimento desta Corte é no sentido de que a Defensoria Pública possui legitimidade para propor ações coletivas em defesa de interesses difusos, coletivos ou individuais homogêneos[...]". (STJ, AgRg no REsp 1404305/RJ, Rel. Min. Mauro Campbell Marques, $2^{\mathrm{a}}$ T., j. 25/8/2015, DJe 3/9/2015)
} 
Desse modo, a legitimidade da Defensoria Pública, na seara coletiva, para o STF, por meio do recente entendimento jurisprudencial consolidado, se configura sob a égide da pertinência temática ${ }^{29}$ onde:

[...] a Defensoria Pública poderá ajuizar qualquer ação para tutela de interesses difusos, coletivos e individuais homogêneos que tenham repercussão em interesses dos necessitados. Não será necessário que a ação coletiva se volte à tutela exclusiva dos necessitados, mas sim que a sua solução repercuta diretamente na esfera jurídica dos necessitados, ainda que também possa operar efeitos perante outros sujeitos. (MARINONI; MITIDIERO; ARENHART, 2015,p. 417)

Pelo exposto, a ausência de exigibilidade de beneficiários exclusivamente pertencentes à coletividade hipossuficiente financeiramente das ações coletivas concretiza a aplicação da teoria da adequacy of representation, pois a legitimidade conferida ao ente defensor se inter-relaciona com o estado de necessidade por intermédio do caso concreto, aplicando as funções institucionais de maneira ampla, ao evidenciar o nexo causal entre o objeto da demanda coletiva e a presença de titulares em estado de hipossuficiência, seja ela financeira, organizacional ou jurídica. Havendo, nesse sentido, uma ampliação exegética da pertinência temática de atuação institucional da Defensoria Pública.

Atuação da Defensoria, na defesa de direitos difusos e coletivos, é mais um meio idôneo para "prevenir a pulverização dos megaconflitos em múltiplas e repetidas ações individuais" (MANCUSO, 2009, p. 147). Com este posicionamento, sem dúvidas, o STF norteou o sistema de justiça em direção ao ideal-democrático-participativo que fomenta a concretização do acesso à justiça e fortalece institucionalmente a Defensoria Pública.

Contudo, não é despiciendo reforçar que a hipossuficiência não se resume meramente na escassez de recursos financeiros ${ }^{30}$, fazendo necessária uma interpretação à luz do princípio da máxima efetividade do acesso à Justiça Coletiva, reconhecendo-se diversos "estados de necessidade" em âmbito coletivo.

\section{CONCLUSÃO}

Com o advento da constitucionalização do processo civil, na busca pela efetivação e a concretização dos direitos, tem-se que a legitimidade para agir, nas demandas da coletividade, adquiriu nova roupagem e acabou se diferenciando do caráter individualista peculiar das demandas individuais, por esse motivo o processo coletivo conquista crescente importância prática na atualidade, devendo o ordenamento se atentar para a aplicabilidade de princípios como: $\mathrm{O}$ do Interesse Jurisdicional no conhecimento do mérito do processo coletivo; Da Máxima Prioridade Jurisdicional da Tutela Jurisdicional Coletiva; E o da Presunção da Legitimidade ad causam Ativa nas Demandas Coletivas, pois instrumentalizam o entendimento nuclear do processo coletivo.

Nesse contexto, a ação civil pública, se revela como um valoroso instrumento processual em defesa da coletividade, sendo relevante tanto no sentido jurídico (visto que fortalece a

\footnotetext{
${ }^{29}$ Conforme a seguinte transcrição de trecho do voto da Ministra Relatora: "a presunção de que, no rol dos afetados pelos resultados da ação coletiva, constem pessoas necessitadas é suficiente a justificar a legitimidade da Defensoria Pública" (STF, ADI 3943, Rel. Min. CÁRMEN LÚCIA, Tribunal Pleno, j. 7/5/2015, ACÓRDÃO ELETRÔNICO DJe-154, div. 5-8-2015 p. 6-8-2015).(grifou-se)

${ }^{30}$ Este foi o entendimento do TJ/SP no processo no 0035539-14.2013.8.26.0053., visto que: “A Defensoria Pública deve atuar não só em favor dos economicamente hipossuficientes, mas também daqueles que ostentam posição de vulnerabilidade organizacional e jurídica".(grifou-se)".
}

Revista de Direito Brasileira | São Paulo, SP | v. 15 | n. 6 | p. 337 - 353 | set./dez. 2016 
segurança jurídica e a credibilidade do Poder Judiciário, ao franquear de maneira democrática a legitimidade ativa para a sua proposição) quanto no sentido educacional da sociedade civil (visto que na grande maioria das vezes os entes públicos estão pólo passivo, mesmo que de forma subsidiária, tendo como objeto da lide alguma obrigação de fazer ou não fazer). Com isso, se revela um essencial instrumento para democratização do acesso à justiça, pois consiste em ser a mais eficiente medida processual para a defesa dos direitos difusos e coletivos.

A atuação da Defensoria Pública, na defesa de direitos difusos e coletivos, é mais um meio idôneo para diluir a pulverização dos conflitos (ocasionada pelas repetidas ações individuais propostas ao Judiciário), que não pode encontrar óbice na restrição da interpretação da terminologia "hipossuficiência", assim como em precárias estruturas físicas. Deve-se, pois fortalecer institucionalmente a Defensoria, haja vista que fortalecimento da Defensoria Pública é sinônimo de democratização do acesso à justiça e concretização dos direitos fundamentais.

Nesta toada, o recente julgamento da ADIn 3.943, tendo o Supremo Tribunal Federal posicionamento favorável à legitimidade ativa da Defensoria Pública, na defesa dos direitos difusos, caracterizou-se como um grande avanço para o sistema de justiça em direção ao idealdemocrático-participativo fomentando a concretização do acesso à justiça, tendo em vista que a interpretação conferida pelo STF à divergência jurisprudencial levantada acerca da legitimidade ativa da Defensoria para tutelar direitos coletivos e difusos é compatível com a teoria da adequacy of representation, pois amplia a pertinência temática de atuação na seara coletiva, garantindo a efetivação dos direitos fundamentais e possibilitando o acesso à justiça, nos moldes da Constituição Federal, permitindo assim, maior estruturação e fortalecimento da Defensoria Pública.

Salienta-se que a descentralização da atuação do Ministério Público, à luz da ausência de competência exclusiva para a proposição, é salutar a manutenção das bases do Estado Democrático de Direito, em respeito à solidariedade (art. $1^{\circ}$, inc. III, CF), bem como em respeito à concorrência-disjuntiva para a proposição de ações civis públicas.

Destaca-se que com o emergente posicionamento jurisprudencial, o conceito de hipossuficiência deve ser ampliado, não se limitando somente à insuficiência de recursos financeiros, garantindo a proteção institucional daqueles que ostentam posição de vulnerabilidade organizacional e jurídica à luz de um acesso à justiça amplo e da efetivação dos direitos fundamentais.

Sob essa perspectiva, é possível alcançar, no presente trabalho, o entendimento de que torna-se inviável, hodiernamente, sob a ótica constitucional, vedar o uso da ação civil pública por parte da Defensoria na defesa dos direitos difusos e coletivos, na medida em que este órgão conquista cada vez mais espaço no cenário de proteção jurídica. Entretanto, observa-se que esta legitimidade não deve ser conferida de maneira desproporcional, afinal para nenhum ente legitimado é conferida isenção de pertinência temática, razão pela qual torna-se compatível a aplicação da adequacy of representation para que se possa analisar, no caso concreto, a legitimidade ativa para a propositura da ação, estando, consequentemente, legitimada a atuar, ainda que pessoas abastadas se beneficiem dos efeitos da ação. Portanto, defende-se que a atuação da Defensoria Pública, na seara coletiva, deva ocorrer de forma ampla, para tutelar, em juízo, direitos coletivos e difusos em favor de qualquer grupo, desde que dentre os tutelados haja a possível probabilidade da existência de indivíduos pertencentes a um grupo de necessitados, analisados por meio de um sentido amplo de interpretação exegética, ou seja, não somente os necessitados econômicos. 


\section{REFERÊNCIAS}

APELAÇÃO CÍVEL. Sexta Câmara. Apelação 0035539-14.2013.8.26.0053.TRIBUNAL DE JUSTIÇA DE SÃO PAULO. Apelante: Fazenda do Estado de São Paulo. Apelado Defensoria Pública do Estado de São Paulo. Processo no 0035539-14.2013.8.26.0053.

BONE, Robert C. Rethinking the "day in court" ideal and non-party preclusion, New York University Law review, v. 67, 1992.

BRASIL. Constituição (1988). Constituição da República Federativa do Brasil. Brasília, DF, Senado, 1998 .

- Lei n. 7.347, de 24 de julho de 1985. "Disciplina a ação civil pública de responsabilidade por danos causados ao meio ambiente, ao consumidor, a bens e direitos de valor artístico, estético, histórico, turístico e paisagismo e dá outras providências." Disponível em < http://www.planalto.gov.br/ccivil_03/leis/L7347orig.htm > Acesso em jul. 2016.

Lei n. 11.448, de 15 de janeiro de 2007. "Altera o art. $5^{\circ}$ da Lei n. 7.347/85, que disciplina a ação civil pública, legitimando para a sua propositura a Defensoria Pública." Disponível em < http://www.planalto.gov.br/ccivil_03/_ato2007-2010/2007/lei/111448.htm> Acesso em jul. 2016.

- Câmara dos Deputados. Proposta de Emenda à Constituição $n^{\circ} 247$, de 2013, altera o

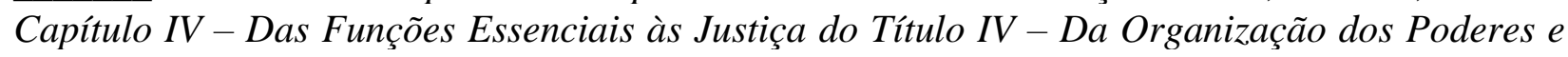
acrescenta artigo ao ato das Disposições Constitucionais. Relator o deputado Amauri Teixeira.< http://www.camara.gov.br/proposicoesWeb/prop_mostrarintegra? codteor $=1135807 \&$ filename $=\mathrm{T}$ ramitacao-PEC+247/2013 > Acesso em 15 abr 2016. Texto original

BURLE FILHO, José Emmanuel. Ação Civil Pública. Instrumento de educação democrática. In: AÇÃO civil pública: lei 7.347/1985-15 anos. São Paulo: Revistas dos Tribunais, 2001. ISBN 8520319904.

CANOTILHO, José Joaquim Gomes.Direito constitucional e teoria da constituição. Coimbra: Almedina, 2003.

CAPPELLETTI, Mauro; GARTH, Bryant. Acesso à justiça. Porto Alegre:.Fabris, 2002

, Mauro. GARTH, Bryant G; Foreward: Access to Justice as a Focus of Research.

Maurer School of Law: Indiana University 1981. <http://www.repository.law.indiana.edu/cgi/viewcontent.cgi? $\quad$ article=2133\&context=facpub $>$ Acesso em abr. 2016.

Alegre: Frabis, 1988.

, Mauro; GARTH, Bryan. Acesso à Justiça..Trad. Ellen Gracie Northfleet. Porto

CINTRA, Antônio Carlos de Araújo; GRINOVER, Ada Pellegrini; DINAMARCO, Cândido Rangel. Teoria Geral do Processo. 15ªEd. São Paulo: Malheiros, 1999. 
DEFENSORIA PÚBLICA DO ESTADO DO AMAZONAS. Locais de atendimento. <www.defensoria.am.gov.br/?q=275-conteudo-42440-Locais\%20de\%20Atendimento > Acesso Mar. 2016

DEFENSORIA PÚBLICA DO ESTADO DO TOCANTINS. NAC - Núcleo Especializado de Direitos Difusos, Coletivos e Individuais Homogêneos ou Núcleo de Ações Coletivas. 2016. < http://ww2.defensoria.to.gov.br/site_home/pagina/16975 > Acesso em Mar. 2016

FAVELA, José Ovalle. Tendencias actuales em el Derecho Procesal Civil. In: FERNÁNDEZ, José Luis Soberanes(Compilador). Tendencias actuales del Derecho. México, D.F.: Fondo de Cultura Económica, 2001

FENSTERSEIFER, Tiago. Defensoria Pública, direitos fundamentais e ação civil pública: A tutela coletiva dos direitos fundamentais (liberais, sociais e ecológicos) dos indivíduos e grupos sociais necessitados. $1^{\text {a }}$ Ed.São Paulo: Saraiva, 2015.

FERRAZ, Cristina. Legitimidade Da Defensoria Pública Na Ação Civil Pública À Luz Do Acesso À Justiça. Direito e Justiça (URI), v. 13, p. 35-52, 2013; Meio de divulgação: Digital. Homepage: Série: unica; ISSN/ISBN: 16768558. Disponível em < http://srvapp2s.santoangelo.uri.br/seer/index.php/direito_e_justica/article/view/1115 > acesso em mar. 2016.

GENEHR, Fabiana Pacheco. O Assédio Processual no Processo do Trabalho: uma questão de Justiça. LTr. Suplemento Trabalhista, São Paulo, v. 51, p. 151-158, 2015.

GRINOVER, Ada Pellegrini. Novas tendências do direito processual. Rio de Janeiro: Forense Universitária,1990.

, Ada Pellegrini. Parecer a respeito da constitucionalidade da Lei n. 11.448/2007, que conferiu legitimidade ampla a Defensoria Pública para a acáo civil pública. In: SOUSA, José Augusto Garcia de (Coord.). Urna nova Defensoría Pública pede passagem: reflexóes sobre a Lei Complementar n. 132/2009. Rio de Janeiro: Lumen Juris, 2011, p. 483. Disponível também em: < http://www.anadep.org.br/wtksite/cms/conteudo/4820/Documento10.pdf >. Acesso em mar. 2016.

GRINOVER, Ada Pellegrinni; MENDES, Aluisio Goncalves de Castro; e WATANABE, Kazuo (Coords.). Direito processual coletivo e o anteprojeto de Código Brasileiro de Processos Coletivos. Sao Paulo: Revista dos Tribunais, 2007.

INSTITUTO DE PESQUISA ECONÔMICA APLICADA (IPEA). Mapa da Defensoría Pública no Brasil Brasília: IPEA, 2013 Disponível em <http://www.ipea.gov.br/sites/mapadefensoria/defensoresnosestados $>$ Acesso em mar. 2016.

MANCUSO, Rodolfo de Camargo. Acesso à justiça: condicionantes legítimas e ilegítimas. $2^{\mathrm{a}}$ Ed.São Paulo. Revista dos Tribunais, 2015

, Rodolfo de Camargo. Ação civil pública: em defesa do meio ambiente, do patrimônio cultural e dos consumidores. Lei 7.347/1985 e legislação complementar.11 ${ }^{\text {a }}$ Ed. São Paulo: Revista dos Tribunais, 2009. 
Tribunais, 2006.

, Rodolfo de Camargo. Jurisdição Coletiva e Coisa Julgada. São Paulo: Revista dos

MARINONI, Luiz Guilherme; MITIDIERO, Daniel; ARENHART, Sérgio Cruz. Novo curso de processo civil: tutela dos direitos mediante procedimentos diferenciados. São Paulo, SP: Revista dos Tribunais, 2015. v. 3 ISBN 978-85203-6708-7.

MAZZILLI, Hugo Nigro. A defesa dos interesses difusos em juízo. $28^{a}$ Ed. São Paulo: Saraiva, 2015. , Hugo Nigro. "O Ministério Público no Estatuto da Criança e do Adolescente." Revista Jurídica. 181:21, Nov. 1992, ano 40.

MINAS GERAIS. Tribunal de Justiça. Apelação Cível. Processo $n^{o}$ 1.0024.09.701231-4/001. (julgado em: 17/05/2011. Comarca de Belo Horizonte. $7^{\text {a }}$ CÂMARA CÍVEL. Apelante: Defensoria Pública Estado Minas Gerais - Apelado(A)(S): Município Belo Horizonte - Relator: Exmo. Sr. Des. Belizário De Lacerda.

RAMOS, André de Carvalho. Curso de Direitos Humanos. $2^{\text {a }}$ Ed. São Paulo, Saraiva, 2015.

SARLET, I. W. A Eficácia dos Direitos Fundamentais: Uma teoria geral dos direitos fundamentais na perspectiva constitucional. 11. ed. Porto Alegre/RS: Livraria do Advogado, 2012.

SILVA, José Afonso da. Direito Constitucional Positivo. 35 a Ed. São Paulo: Malheiros Editores, 2012.

SILVA, José Afonso da. Comentário contextual à Constituição. 5. ed. São Paulo: Malheiros, 2008.

SUPREMO TRIBUNAL FEDERAL, AÇÃO DIRETA DE INCONSTITUCIONALIDADE $n^{o}$ 3943, Rel. Min. CÁRMEN LÚCIA, Tribunal Pleno, j. 7/5/2015, ACÓRDÃO ELETRÔNICO DJe-154, div. 5-8-2015 p. 6-8-2015. Disponível em <http://www.stf.jus.br/portal/processo/verProcessoPeca.asp?id=307366526\&tipoApp=.pdf > Acesso em mar. 2016.

THEODORO JÚNIOR, Humberto. Curso de Direito Processual Civil: procedimentos especiais. Vol. II. 50 . Ed. Rio de Janeiro: Forense, 202016.

VERRI, Marina Mezzavilla. Legitimidade da Defensoria Pública na Ação Civil Pública: Limites. São Paulo: Ribeirão Preto Gráfica e Editora, 2008.

WOOLLEY, Patrick. Rethink the adequacy of adequate representation, Texas Law Review, v. $75,1997$.

ZAVASCKI, Teori Albino. Processo Coletivo: tutela de direitos coletivos e tutela coletiva de direitos. São Paulo: Revista dos Tribunais, 2014. 